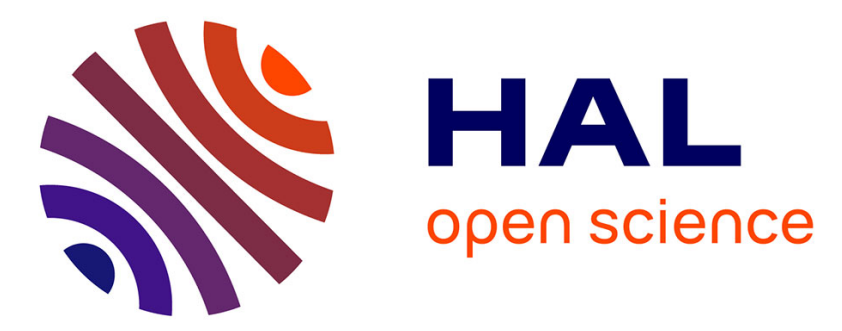

\title{
Tobacco smoking and other substance use disorders associated with recurrent suicide attempts in bipolar disorder
}

R. Icick, I. Melle, B. Etain, P.A. Ringen, S.R. Aminoff, M. Leboyer, M. Aas, C. Henry, T.D. Bjella, O.A. Andreassen, et al.

\section{To cite this version:}

R. Icick, I. Melle, B. Etain, P.A. Ringen, S.R. Aminoff, et al.. Tobacco smoking and other substance use disorders associated with recurrent suicide attempts in bipolar disorder. Journal of Affective Disorders, 2019, 256, pp.348 - 357. 10.1016/j.jad.2019.05.075 . hal-03484961

\section{HAL Id: hal-03484961 https://hal.science/hal-03484961}

Submitted on 20 Dec 2021

HAL is a multi-disciplinary open access archive for the deposit and dissemination of scientific research documents, whether they are published or not. The documents may come from teaching and research institutions in France or abroad, or from public or private research centers.
L'archive ouverte pluridisciplinaire HAL, est destinée au dépôt et à la diffusion de documents scientifiques de niveau recherche, publiés ou non, émanant des établissements d'enseignement et de recherche français ou étrangers, des laboratoires publics ou privés.

\section{(c) (1) $\$$}

Distributed under a Creative Commons Attribution - NonCommerciall 4.0 International 


\section{Tobacco Smoking and other Substance Use Disorders Associated with Recurrent Suicide}

\section{Attempts in Bipolar Disorder}

R. Icick ${ }^{1,2,3,4,5^{*}}$, I. Melle $^{6,7}$, B. Etain ${ }^{1,2,3,4,5}$, P.A. Ringen ${ }^{6}$, S.R. Aminoff ${ }^{7,8}$, M. Leboyer ${ }^{4,5,9,10}$, M.

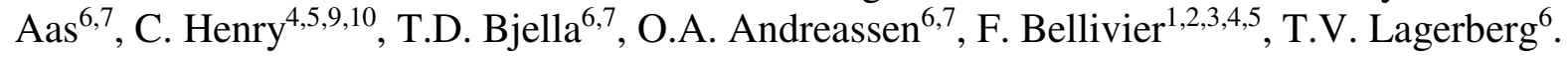

${ }^{1}$ Inserm, U1144, Paris, F-75006, France ;

${ }^{2}$ Paris Diderot University, UMR-S 1144, Paris, F-75013, France ;

${ }^{3}$ Assistance Publique - Hôpitaux de Paris, University Hospitals Saint-Louis - Lariboisière - F. Widal, Departement of Psychiatry and Addiction Medicine, Paris, F-75010, France;

${ }^{4}$ FondaMental Foundation, Créteil, F-94000, France;

${ }^{5}$ LabEx 'Bio-Psy', 17 rue du Fer à Moulin, 75005 Paris, France.

${ }^{6}$ NORMENT, KG Jebsen Centre for Psychosis Research, Division of Mental Health and Addiction, Oslo University Hospital, Oslo, Norway;

${ }^{7}$ NORMENT, KG Jebsen Centre for Psychosis Research, Institute of Clinical Medicine, University of Oslo, Oslo, Norway;

${ }^{8}$ Department of Specialized Inpatient Treatment, Division of Mental Health Services, Akershus University Hospital, Norway;

${ }^{9}$ Inserm U955, Psychiatric Genetics Team, Créteil, F-94000, France ;

${ }^{10}$ Paris Est University, Faculty of medicine, Créteil, F-94000, France ;

${ }^{11}$ Assistance Publique - Hôpitaux de Paris, University Hospitals Henri Mondor, DHU PePsy, Psychiatry Center, Créteil, F-94000, France.

*Corresponding author : romain.icick@aphp.fr. CSAPA «Espace Murger », Département de Psychiatrie et de Médecine Addictologique, Hôpital Fernand Widal, 200 rue du Faubourg Saint-Denis, 75010 Paris, France. Tel: +33140054275 / Fax : +33140054213. 


\section{Abstract}

Background: Suicide attempts (SA) are more frequent in bipolar disorder (BD) than in most other mental disorders. Prevention strategies would benefit from identifying the risk factors of SA recurrence in BD. Substance use disorders (SUD) (including tobacco-related) are strongly associated with both $\mathrm{BD}$ and $\mathrm{SA}$, however, their specific role for the recurrence of SA in BD remains inadequately investigated. Thus, we tested if tobacco smoking - with or without other SUDs - was independently associated with recurrent SA in BD. Methods: 916 patients from France and Norway with ascertained diagnoses of BD and reliable data about SA and SUD were classified as having no, single, or recurrent $(\geq 2)$ SA. Five SUD groups were built according to the presence/absence/combination of tobacco, alcohol (AUD) and cannabis use disorders. Multinomial logistic regression was used to identify the correlates of SA recurrence. Results: 338 (37\%) individuals reported at least one SA, half of whom (173, $51 \%$ ) reported recurrence. SUD comorbidity was: tobacco smoking only, 397 (43\%), tobacco smoking with at least another SUD, 179 (20\%). Regression analysis showed that tobacco smoking, both alone and comorbid with AUD, depressive polarity of BD onset and female gender were independently associated with recurrent SA. Limitations: Lack of data regarding the relative courses of SA and SUD and cross-national differences in main variables. Conclusion: tobacco smoking with- or without additional SUD can be important risk factors of $\mathrm{SA}$ recurrence in $\mathrm{BD}$, which is likely to inform both research and prevention strategies.

Keywords: bipolar disorder; substance use disorder; tobacco smoking; alcohol; cannabis; suicide attempt; recurrent suicide attempts; comorbidity; dual disorder.

Metrics: word count - abstract $=243$; manuscript $=4876$; number of tables $=3$; number of figures $=3$; number of supplementary tables $=3$; number of supplementary figures $=0$; number of supplementary methods file $=2$. 


\section{Introduction}

The lifetime prevalence of attempted (SA) and completed suicides is higher in bipolar disorder (BD) than in most other mental disorders: 50\% for SA (Singhal et al., 2014) and 11$19 \%$ for completed suicide (Pompili et al., 2013). This corresponds to a 20-30 fold risk for SA in BD (Costa et al., 2015), and to a suicide-specific standardized mortality rate of 14.4 [95\% confidence interval (CI) 12.4-16.8] (Hayes et al., 2015). The risk factors for SA in BD [see (Schaffer et al., 2015) for review] include longer illness duration (especially untreated phases), family history of suicidal behavior, depressive polarity at onset and as the predominant polarity over the course of $\mathrm{BD}$, in addition to comorbidity with addictive and anxiety disorders. SAs occur 25 times more often during depressive episodes than during euthymia (Jylhä et al., 2016).

Above all, a history of SA remains the strongest predictor for future SA and completed suicides. It has been prospectively observed that each attempt increased the probability of repetition by about 30\% in people with major mood disorders (Oquendo et al., 2002). Recurrent SAs [defined as having attempted suicide twice or more in a lifetime (Large et al., 2016)] are also associated with a significant further increase in completed suicides. Importantly, the lethal intent or medical seriousness of SAs does not decrease with the number of repetitions in BD (Michaelis et al., 2003). Comparisons between recurrent vs. single suicide attempters have mostly been conducted in non-BD samples. Overall, recurrent SAs are associated with psychiatric (Lopez-Castroman et al., 2011; Monnin et al., 2012; Perquier et al., 2017) and non-psychiatric comorbidities (Vajda and Steinbeck, 2000; Zatzick et al., 2017). They are also associated with high levels of hopelessness, hostility and aggressiveness (Sher et al., 2017) which, altogether, indicate that recurrent SA are associated with a high morbidity load. Both SUDs (Mitchell and Potenza, 2014) and SAs (American Association of Suicidology, 2013) have been associated with trait-impulsivity. As such, it 
could represent a common denominator of the risk of SA hypothesized to be increased in BDSUD individuals. Of note, impulsivity is a highly complex construct (Dalley and Robbins, 2017) and there have been associations of various SA subtypes with different impulsivity subtypes, the most constant likely being the relationship between motor impulsivity and recurrent SAs (Colborn et al., 2017). However, several studies also reported a lack of association between impulsivity and SA, regardless of SA subtypes (recurrent, violent) in BD (Etain et al., 2013; Perroud et al., 2011). Regarding sociodemographic characteristics, a family history of suicidal behavior (Liu et al., 2017), female gender, younger age, and living alone (Lopez-Castroman et al., 2011; Monnin et al., 2012; Zahl and Hawton, 2004) have been associated with recurrent SA, although most these associations were inconstant across studies. Substance use disorders (SUD) seemed particularly involved in the recurrence of SA in such non-BD samples, e.g., in follow-up studies based on an index attempt assessed in the emergency room (Lopez-Castroman et al., 2011; Monnin et al., 2012). However, there are noticeable substance-specific differences in associations between SAs and SUD. For instance, alcohol use disorders (AUD) and SUD [other than cannabis use disorders (CUD)] have been repeatedly associated with SA (Østergaard et al., 2017), but the study of CUD have so far yielded equivocal findings (Carrà et al., 2015; Østergaard et al., 2017). This may be due to the confounding effects of the almost constant overlap between tobacco and cannabis use, which are often overlooked in cannabis studies (Peters et al., 2012).

Identifying the characteristics associated with recurrent SAs in BD represents a crucial step to decrease the burden of suicidal behavior in this population (Malhi et al., 2018), as was suggested for other clinical conditions (Lopez-Castroman et al., 2016b; Sher et al., 2017). Yet, to our knowledge, only two studies to date have addressed this issue as their main objective. The first (Michaelis et al., 2003) examined the lifetime characteristics of first $v s$. recurrent attempters assessed after an index SA. SUDs were not associated with the presence vs. 
absence of previous SA, however, the study lacked statistical power $(\mathrm{N}=52)$. The second (Arici et al., 2018) identified psychiatric comorbidity and living alone as specific risk factors for recurrent $\mathrm{SA}$, in a larger sample ( $\mathrm{N}=362$, including 95 suicide attempters). The most frequent comorbidity pattern associated with recurrent SA was 'anxiety + SUD', but separate results for SUDs were not reported. Two studies also reported associations between recurrent SA and repeated and refractory mood episodes [especially mixed states (Goldberg et al., 1998)], and having a depressive onset of BD (Neves et al., 2009), respectively. Also relevant to the focus of the present study is the frequently reported association between mixed states and SUDs in bipolar disorders (Schaffer et al., 2015). As for onset/predominant polarity, a complex pattern emerged from extant literature. In a study comparing manic to depressive polarity at onset, authors reported that SUD were associated with the former and suicide attempts to the latter (Popovic et al., 2014). Comparing three groups of BD without SUD, BDAUD and BD-other SUD, another study reported that BD without SUD had a more frequent manic predominant polarity whilst BD with any SUD were associated with depressive polarity (Janiri et al., 2017). Given the strong association between mixed states and SUD with inconstant findings regarding onset/predominant polarity, further study was warranted to address these course specifiers of BD in relation to suicide attempts.

Thirty to seventy percent (30-70\%) of individuals with BD have at least one comorbid SUD (Hunt et al., 2016a, 2016b) [including tobacco smoking/nicotine dependence (Thomson et al., 2015)], and these comorbidities have been repeatedly associated with suicidal behavior (Carrà et al., 2014; Schaffer et al., 2015). A growing body of evidence also designates tobacco smoking as a potentially independent risk factor for SA in BD (Ducasse et al., 2015; Ostacher et al., 2009) and, in non-BD samples, specific associations between tobacco smoking and recurrent SA have been reported (Icick et al., 2018; Lopez-Castroman et al., 2016a). However, according to our literature search (including 'nicotine dependence' or 'cigarette 
smoking' as entry terms), whether tobacco smoking is independently associated with recurrent $\mathrm{SA}$ in $\mathrm{BD}$ remains to be investigated, especially as regards former $v s$. current smoking.

In summary, recurrent SAs represent a distinct and burdensome suicidal phenotype in BD, the prevention of which would largely benefit from a better characterization of the addictive comorbidity patterns associated with recurrent SA in this high-risk population. Therefore, we aimed at studying the effects of comorbid tobacco smoking and other common SUDs in the recurrence of SAs in a large sample of patients with BD. More specifically, we investigated (i) whether tobacco smoking was associated with recurrent SA independently from AUD and CUD and (ii) if increasing SUD burden, i.e. presenting with one or more SUDs in addition to tobacco smoking, was associated with further increased risk for recurrent SA. We hypothesized that the risk of recurrent SA would increase with the number of SUDs comorbid with tobacco smoking.

\section{Methods}

This was a cross-sectional study including a multicenter sample.

\section{Participants (Figure 1)}

Treatment-seeking individuals presenting to specialized clinics in Norway and France, as inpatients or outpatients, and with symptoms suggesting the presence of BD were screened for the study. Inclusion criteria were: (i) age $\geq 18$ years; (ii) meeting DSM-IV criteria for a diagnosis of BD-I or BD-II disorder; and (iii) willingness and ability to provide written informed consent. In France, additional criteria for inclusion were: (i) being euthymic at inclusion, as defined by a Montgomery-Asberg Depression Rating Scale (MADRS) score $\leq 8$ (Montgomery and Asberg, 1979) and a Mania Rating Scale (YMRS) score of $\leq 5$ (Young et 
al., 1978); (ii) mastering the French language; and (iii) having at least three grandparents born in France due to the initial purpose of the study (genetic analyses). In Norway, euthymia was not an inclusion criterion, but patients had to be clinically stable and to master a Scandinavian language. Additional inclusion criteria in Norway were: (i) absence of history of severe head trauma and (ii) IQ $\geq 70$. In both samples, lifetime schizophrenia was also an exclusion criterion, so that there were no cases with affective psychosis/schizo-affective disorder in the final sample.

Thirty-three cases were excluded due to missing data about SA (17 for lifetime SA and 16 for the number of SA), 35 because they had missing data regarding SUD diagnoses, and 17 due to missing data about smoking status. Given their small number and in order to limit the number of subgroups, we also excluded non-tobacco smokers with AUD (N=27) and/or CUD (N=5) and/or other SUDs $(\mathrm{N}=49)$, leaving a final sample of 916 participants. The flowchart of participant selection and incomplete cases exclusion is presented Figure 1.

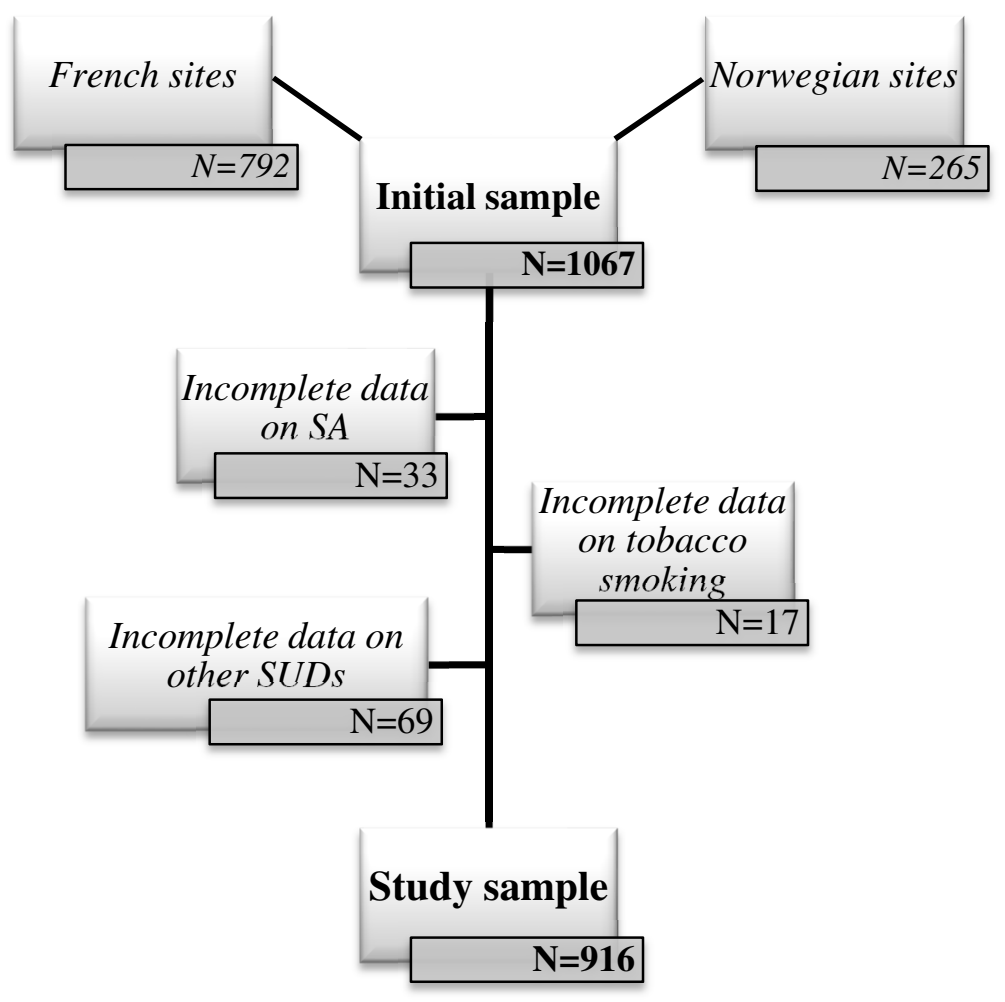




\section{Figure 1: flowchart for sample selection}

SA, suicide attempt; SUD, substance use disorders.

Written informed consent was obtained from all participants in both countries. This involved being registered in the database and having one's de-identified data analyzed for research purposes. In France, the Research Ethics Board of Pitié-Salpêtrière Hospital reviewed and approved this study. In Norway, the project was approved by the Regional Committee for Medical Research Ethics and the Norwegian Data Inspectorate.

\section{Clinical Assessment}

In both countries, trained psychiatrists, medical doctors and clinical psychologists carried out the clinical assessments. After the verification of euthymia, defined as a Motgomery-Asberg Depression Rating Scale (MADRS) < 8 (Montgomery and Asberg, 1979) and Young Mania Rating Scale (YMRS) < 4 (Young et al., 1978), French participants were interviewed with the Diagnostic Interview for Genetic Studies (DIGS) (Preisig et al., 1999). In the Norwegian sample, diagnoses were established using the Structured Clinical Interview for DSM-IV Axis I disorders (SCID-I), modules A to E. Diagnostic concordance between the DIGS and the SCID has previously been reported to be excellent (Aas et al., 2014), and these questionnaires have been validated in French (Preisig et al., 1999) and Norwegian language (Ringen et al., 2008), respectively. Thus, they provided reliable lifetime DSM-IV Axis I diagnoses in both samples.

\section{Bipolar illness}

Participants were asked about their age at first major mood episode and their respective lifetime numbers of depressive, hypomanic, manic and mixed episodes. The lifetime occurrence of psychotic symptoms during a mood episode was also collected. The polarity and age at onset (AAO) of the first major depressive, manic, hypomanic or mixed episode 
defined those of onset of $\mathrm{BD}$ [depressive vs. (hypo)manic/mixed]. AAO of BD was used to calculate duration of illness until age at inclusion in the study. The minimum duration of BD was set to 1 year because $1 /$ of the way it was calculated by using age $v s$. date data and $2 /$ in order to avoid division by 0 in our estimate of the relative lifetime exposure of individuals to their bipolar illness, obtained by dividing the duration of bipolar illness by participants' age at interview ('\% of lifetime spent with BD'). Rates of mood episodes and hospital stays due to a mood episode per year of $\mathrm{BD}$ were calculated from the number of (hypo)manic and/or depressive episodes / hospital stays divided by the number of illness years (one per type of episode and one for the total number of episodes). These calculations were performed in order to limit the right-censoring of events inherent to the study cross-sectional design and to take the duration of exposure to BD into account.

\section{Suicide attempts}

In both countries, history of SA was collected through semi-structured instruments (Supplementary Methods I), SA being identically defined as self-harm with any intent to die (Goodfellow et al., 2017):

- In France, by the relevant section of the DIGS, the opening question being about 'killing oneself'.

- In Norway, by a specific questionnaire derived from a European study of self-harm (CASE-study) following the National Institute for Clinical Excellence (NICE) guidelines (National Collaborating Centre for Mental Health (UK), 2004), and previously used in psychiatric populations (Mork et al., 2013), the opening question being about 'hurting oneself with further specification of the suicidal intent'. 
Participants were then asked how many times they had attempted suicide. SA recurrence was set to "0" for the absence of lifetime SA, "1" if only one SA was reported, and "2" if two or more SAs were reported, which corresponded to recurrent SA.

\section{Substance use assessments}

Tobacco smoking was defined as 'smoking on a daily basis', a widely used and reliable marker of DSM-IV nicotine dependence with low intra-individual variability (Hughes et al., 2017). For current smokers, pack-years (the theoretical number of years during which a subject has smoked 20 cigarettes/day) were also calculated, as a rough estimate of lifetime exposure to tobacco. In the French subsample, lifetime tobacco smoking (former + current) was assessed, while in the Norwegian subsample, only current tobacco smoking was considered. As such, tobacco smokers $(\mathrm{N}=413)$ in the French subsample were both current $(\mathrm{N}=294)$ and former smokers $(\mathrm{N}=119)$, whereas those from the Norwegian subsample were current smokers only $(\mathrm{N}=163)$. Both the DIGS and the SCID generated DSM-IV diagnoses of abuse or dependence to other substances, which were compiled to obtain a single binary variable of 'use disorder' for each substance.

\section{Substance Use Disorder (SUD) groups}

A single 'SUD groups' variable was built according to whether participants reported tobacco smoking and/or were diagnosed with SUDs: (i) neither tobacco smoking nor any other SUD, which was the reference group in our analyses, (ii) tobacco smoking without any other SUD (tobacco), (iii) tobacco smokers with AUD but no CUD (tobacco + AUD), (iv) tobacco smokers without AUD but with CUD (tobacco + CUD) and (v) tobacco smokers with both AUD and CUD (tobacco + AUD + CUD). Groups were mutually exclusive.

\section{Statistics}


Data are described as medians (interquartile range, IQR) since all had non-normal distribution according to the Shapiro-Wilk test (all $p$-values $<0.001$ ), or counts (frequency). Bivariate analyses used Kruskal-Wallis $H$ for quantitative variables or $\mathrm{Chi}^{2}$ for categorical variables. Fisher's exact tests were used when calculation tables for qualitative variables had cells with less than five expected cases. Statistical significance was set at $p<0.05$, two-tailed tests applied to the three groups altogether, with Bonferroni correction for pairwise post hoc tests. In order to discuss the reliability of our findings, we indicate which variables remained statistically significant after Bonferroni correction (21 tests, significant raw $p$ <0.00238).

Multinomial logistic regression was then performed with recurrent SA as a dependent variable (see above). We forced the entry of SUD groups, country of inclusion and the rate of mood episodes per year of illness (as our main objective was to uncover the correlates of SA recurrence that were independent from mood episodes - during which most SA in BD occur) into the regression model. The variables associated with SA groups at $p<0.05$ in bivariate analyses were also entered in the model. In case of collinearity, defined as a variance inflation factor $(\mathrm{VIF})>2.5$, variables were excluded. The model ran twice: once with the absence of SA as the reference group, and once with 'single lifetime SA' as the reference group. This allowed for testing factors that specifically differentiated single and recurrent $\mathrm{SA}$, as previously published (Olié et al., 2015). Models were backward, stepwise based on based on largest to smallest $p$-values for association with recurrent SA. Finally, a sensitivity analysis was conducted by performing both bivariate and regression analyses separately in both countries, which are summarized in the discussion section and presented in Figure 2, Table 1 \& Supplementary Table 2 .

All analyses were conducted with $R$ version 3.5.2 (R Core Team, 2019) through R studio version 1.1.463 (R Studio Team, 2019) for Mac OS® X.12.6. The whole script and a summary of the packages that we used are available in the supplementary methods file. 


\section{Results}

Nine hundred sixteen (916) cases with complete data on SUDs (diagnoses+groups, including tobacco smoking) and SA were eventually analyzed (Figure 1). Cases were 59\% women $(\mathrm{N}=542), 74 \%$ BD-I $(\mathrm{N}=675)$ and 26\% (N=241) BD-II. Four French university-affiliated psychiatry departments recruited 623 (68\%) cases (Créteil, Bordeaux, Marseille, Nancy), the remaining $293(32 \%)$ were recruited across all major hospitals in the Oslo area for the Thematically Organized Psychosis (TOP) Study (Norway). There were 338 (37\%) participants with lifetime SA in the sample, $173(51 \%)$ of whom reported recurrent SA. Three hundred and forty participants $(340,37 \%)$ had neither tobacco smoking nor SUD, 397 (43\%) had tobacco smoking only, $99(11 \%)$ had tobacco smoking+AUD, $42(5 \%)$ had tobacco smoking+CUD and 38 (4\%) had tobacco smoking+AUD+CUD. One-hundred seventy-nine participants (20\%) had tobacco smoking and at least another SUD.

Several variables exhibited cross-national differences (Table 1, Figure 2), namely: age ( $p$ $<0.001)$, marital status $(p<0.001)$, ancestry $(p<0.001)$, AAO and duration of $\mathrm{BD}(p<0.001$, Figures $2 \mathrm{~b} \& 2 \mathrm{~d})$, the number of both any and depressive mood episodes per year of BD ( $p$ $<0.001)$, the presence $(p<0.001)$ and recurrence $(p=0.04)$ of SA, current smoking $(p=0.021)$, smoking pack-years $(p=0.001$, Figure 2a), SUD groups $(p<0.001$, Figure $2 \mathrm{c}$ ) and family history of $\mathrm{BD}(p<0.001)$.

Table 1: Country specific data distribution and cross-national differences in demographic and clinical characteristics

\begin{tabular}{|c|c|c|c|c|c|c|c|}
\hline \multirow{2}{*}{\multicolumn{2}{|c|}{ N $(\%)$ or median (IQR) }} & \multirow{2}{*}{ Norway, $N=293$} & \multirow{2}{*}{ France, $N=623$} & \multirow{2}{*}{ All } & \multicolumn{2}{|c|}{ Norway vs. France } & \multirow{2}{*}{$\begin{array}{c}\text { Sample } \\
\text { size }\end{array}$} \\
\hline & & & & & Statistics $^{\mathrm{a}}$ & $p$-value & \\
\hline \multirow{5}{*}{$\begin{array}{c}\text { Marital } \\
\text { status }\end{array}$} & Gender & $181(62 \%)$ & $361(58 \%)$ & $542(59 \%)$ & 1.06 & 0.304 & 916 \\
\hline & Age & $34(26-44)$ & $42(33-52)$ & $40(30-49.3)$ & 17.695 & $<0.001$ & \\
\hline & Currently married & $73(25 \%)$ & $215(35 \%)$ & $288(32 \%)$ & & & \\
\hline & Divorced/Widowed & $43(15 \%)$ & $381(62 \%)$ & $424(47 \%)$ & 397.38 & $<0.001$ & 910 \\
\hline & Never married & $177(60 \%)$ & $21(3 \%)$ & $198(21 \%)$ & & & \\
\hline \multicolumn{2}{|c|}{ Caucasian ancestry } & $268(91 \%)$ & $613(100 \%)$ & $881(97 \%)$ & 40.4 & $<0.001$ & 909 \\
\hline
\end{tabular}




\begin{tabular}{|c|c|c|c|c|c|c|}
\hline \multirow{2}{*}{$\mathbf{N}(\%)$ or median (IQR) } & \multirow{2}{*}{ Norway, $N=293$} & \multirow{2}{*}{ France, $N=623$} & \multirow{2}{*}{ All } & \multicolumn{2}{|c|}{ Norway vs. France } & \multirow{2}{*}{$\begin{array}{l}\text { Sample } \\
\text { size }\end{array}$} \\
\hline & & & & Statistics $^{\mathrm{a}}$ & $p$-value & \\
\hline Bipolar subtype & $87(30 \%)$ & $154(25 \%)$ & $241(26 \%)$ & 2.29 & 0.13 & 916 \\
\hline Depressive polarity at onset & $162(62 \%)$ & $387(63 \%)$ & $549(63 \%)$ & 0.02 & 0.892 & 877 \\
\hline \multirow{2}{*}{$\begin{array}{c}\text { AAO of BD } \\
\text { Duration of BD }\end{array}$} & $20(16-28)$ & $22(18-31)$ & $22(17-30)$ & 54.558 & $<0.001$ & \multirow{2}{*}{905} \\
\hline & $10(5-19)$ & $15(7-25)$ & $13(6-23)$ & 25.45 & $<0.001$ & \\
\hline $\begin{array}{c}\text { Percent of lifespan spent with } \\
\text { BD }\end{array}$ & $0.33(0.17-0.51)$ & $0.39(0.2-0.56)$ & $0.37(0.2-0.55)$ & 5.95 & $0.015^{\mathrm{b}}$ & 905 \\
\hline MDE / year of BD & $0.43(0.19-1)$ & $0.25(0.12-0.5)$ & $0.29(0.14-0.61)$ & 29.32 & $<0.001$ & 850 \\
\hline $\begin{array}{c}\text { (Hypo)manic episodes / year } \\
\text { of BD }\end{array}$ & $0.38(0.15-1)$ & $0.33(0.14-0.78)$ & $0.33(0.14-0.94)$ & 1.4 & 0.237 & 830 \\
\hline Mood episodes / year of BD & $0.99(0.43-1.81)$ & $0.60(0.32-1.17)$ & $0.67(0.35-1.5)$ & 15.19 & $<0.001$ & 873 \\
\hline Any lifetime SA & $84(29 \%)$ & $254(41 \%)$ & $338(37 \%)$ & 12.02 & 0.001 & 916 \\
\hline Number of SA / year of BD & $0.14(0.06-0.33)$ & $0.1(0.06-0.25)$ & $0.11(0.06-0.27)$ & 4.2 & 0.04 & 338 \\
\hline Recurrent SA & $46(16 \%)$ & $119(19 \%)$ & $165(18 \%)$ & 13.89 & 0.001 & 916 \\
\hline $\begin{array}{c}\text { Ever presented with psychotic } \\
\text { characteristics }\end{array}$ & $156(55 \%)$ & $365(59 \%)$ & $521(58 \%)$ & 1.52 & 0.218 & 903 \\
\hline Current smoking & $163(56 \%)$ & $294(47 \%)$ & $457(50 \%)$ & 5.35 & 0.021 & 916 \\
\hline Smoking: pack/years & $6(0.85-15)$ & $12(5-22)$ & $10(3.4-20)$ & 30.55 & 0.001 & 529 \\
\hline Lifetime AUD & $31(11 \%)$ & $106(17 \%)$ & $137(15 \%)$ & 5.99 & 0.014 & \multirow{2}{*}{916} \\
\hline Lifetime CUD & $19(6 \%)$ & $61(10 \%)$ & $80(9 \%)$ & 2.33 & 0.127 & \\
\hline Family history of BD & $36(13 \%)$ & $220(40 \%)$ & $256(30 \%)$ & 64.62 & $<0.001$ & 841 \\
\hline
\end{tabular}

IQR, interquartile range; AAO, age at onset; SA, suicide attempt; BD, bipolar disorder; MDE, major depressive episode; SUD, substance use disorder; AUD, alcohol use disorder; CUD, cannabis use disorder.

${ }^{\mathrm{a}} \mathrm{Chi}^{2}$ for categorical variables and Kruskal-Wallis $H$ for quantitative variables, unless otherwise specified. ${ }^{b}$ Statistics performed on the $\log$ (BD duration/age).

Figure 2: Factors associated with SA groups according to the country of inclusion 

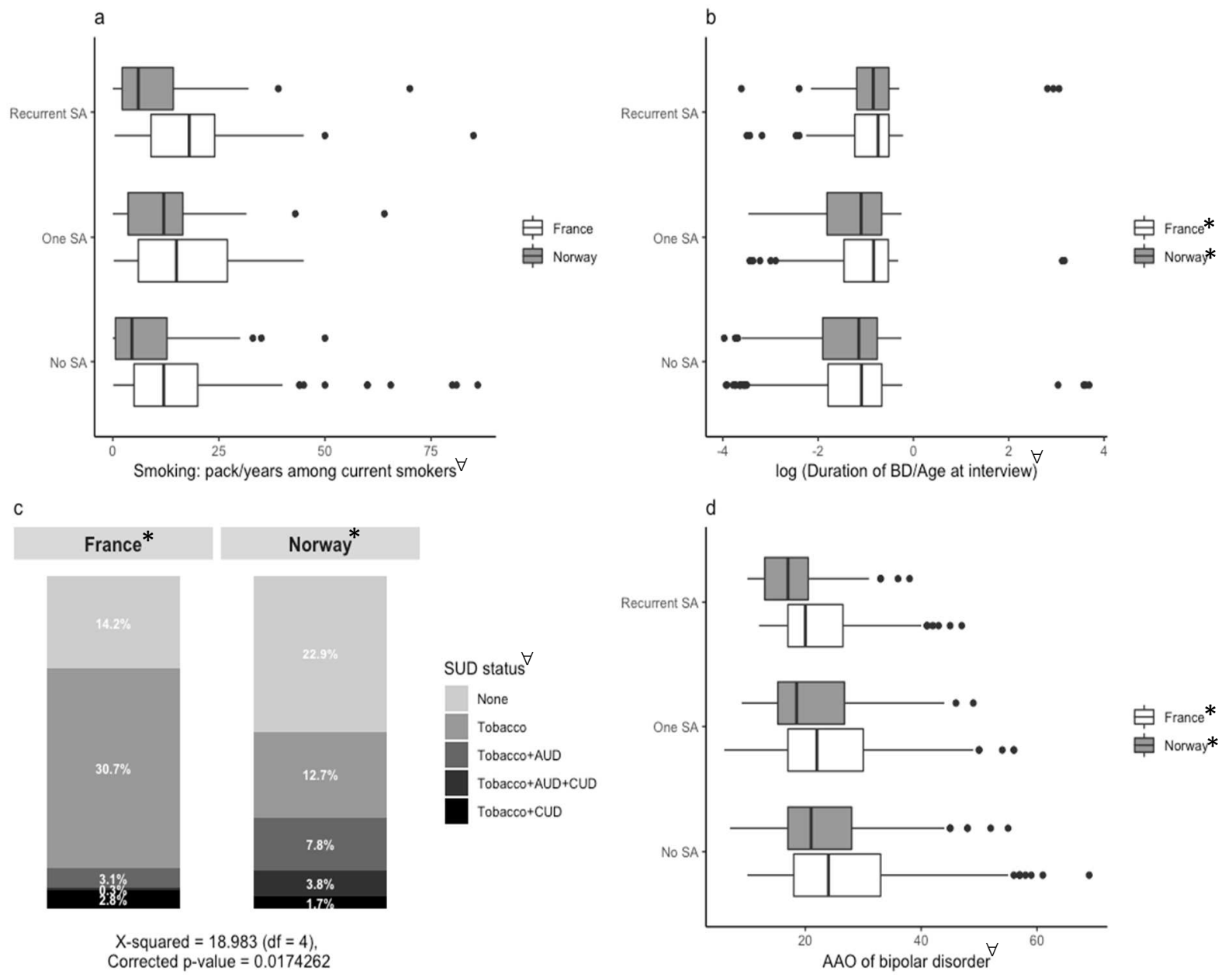

AAO, age at onset; SA, suicide attempt; BD, bipolar disorder; SUD, substance use disorder; AUD, alcohol use disorder; CUD, cannabis use disorder.*Denotes Bonferrroni-corrected $p$-values $<0.05$ according to Kruskal-Wallis test, by country

${ }^{\forall}$ Denotes variable differences between countries at $p<0.05$ 
Table 2: Bivariate tests of sociodemographic and clinical factors for the presence and recurrence of suicide attempts

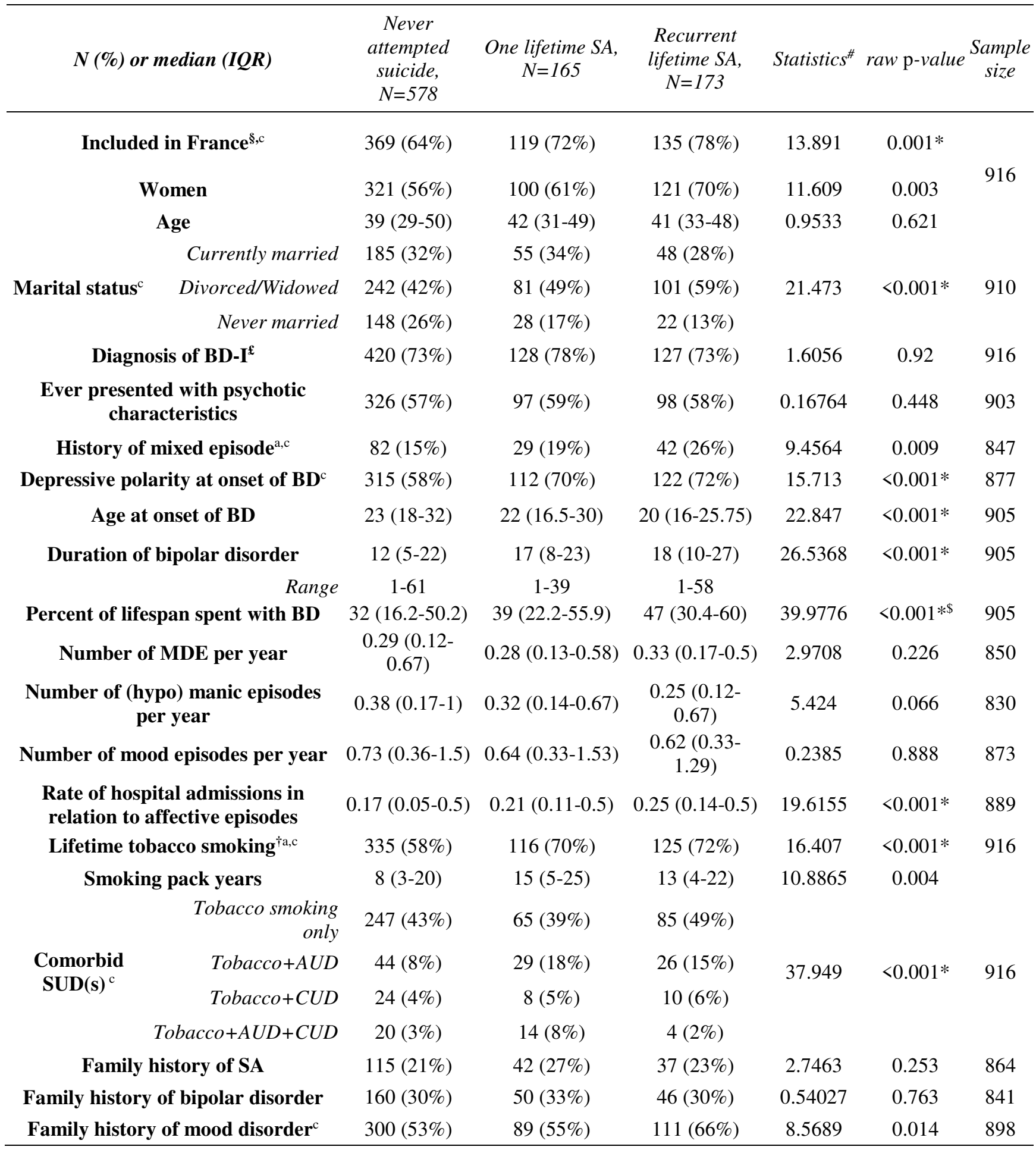

$\mathrm{IQR}$, interquartile range; SA, suicide attempt; $\mathrm{BD}$, bipolar disorder; MDE, major depressive episode; SUD, substance use disorder; AUD, alcohol use disorder; CUD, cannabis use disorder.

${ }^{\#} \mathrm{Chi}^{2}$ for categorical variables and Kruskal-Wallis $H$ for quantitative variables, unless otherwise specified. ${ }^{\S}$ Compared to participants included in Norway. ${ }^{\text {f}}$ Compared to participants with BD-II diagnosis. ${ }^{\$}$ Statistics performed on $\log \left(\mathrm{BD}\right.$ duration/age). ${ }^{\dagger}$ Corresponds to former + current tobacco smokers in France and to current smokers only in Norway. *Denotes $p<0.00238$ (significance after Bonferroni correction for 21 tests). Significant pairwise comparisons after Bonferroni correction are 
flagged with superscript letters: adenotes no SA vs. one SA, bdenotes one SA vs. recurrent SA, ${ }^{\mathrm{c}}$ denotes no SA vs. recurrent SA.

The variables that were significantly associated with SA groups were (Table 2): country of inclusion (France $>$ Norway, $p=0.001$, more frequent in recurrent vs. non-SA), gender (women $>$ men, $p=0.003$ ), marital status (separated $v s$. other statuses, $p<0.001$ ), BD duration and age at onset (respectively shorter and lower in ever suicide attempters, both $p<0.001$ ), history of mixed episode (more frequent in ever suicide attempters, $p=0.0088$ ), the depressive polarity at $\mathrm{BD}$ onset (more frequent in ever suicide attempters, $p<0.001$ ), the rate of hospital admissions in relation to affective episodes $(p<0.001)$, lifetime tobacco smoking (more frequent in ever suicide attempters, $p<0.001$ ), smoking pack-years (higher in single SA vs. both non and recurrent suicide attempters, $p<0.001$ ), SUD status (the comorbidity load seemed higher for all SUD groups in case of single SA, except for tobacco smoking). Recurrent SA were not associated with the yearly episode rate of a specific polarity, so we chose to incorporate that of any mood episode /year as a covariate for regression analysis (see Methods section).

The cumulative proportions of SA groups with respect to SUD status and gender are shown Figure 3a \& 3b, respectively. Fig. 3a illustrates the association between recurrent SA and tobacco smoking without another SUD and that of AUD with any SA, while Fig. 3b shows that, conversely to men, women presented a majority of recurrent $v s$. single SA in the sample. 
Figure 3: Cumulative \% of SA groups according to SUD status (3a) and gender (3b)
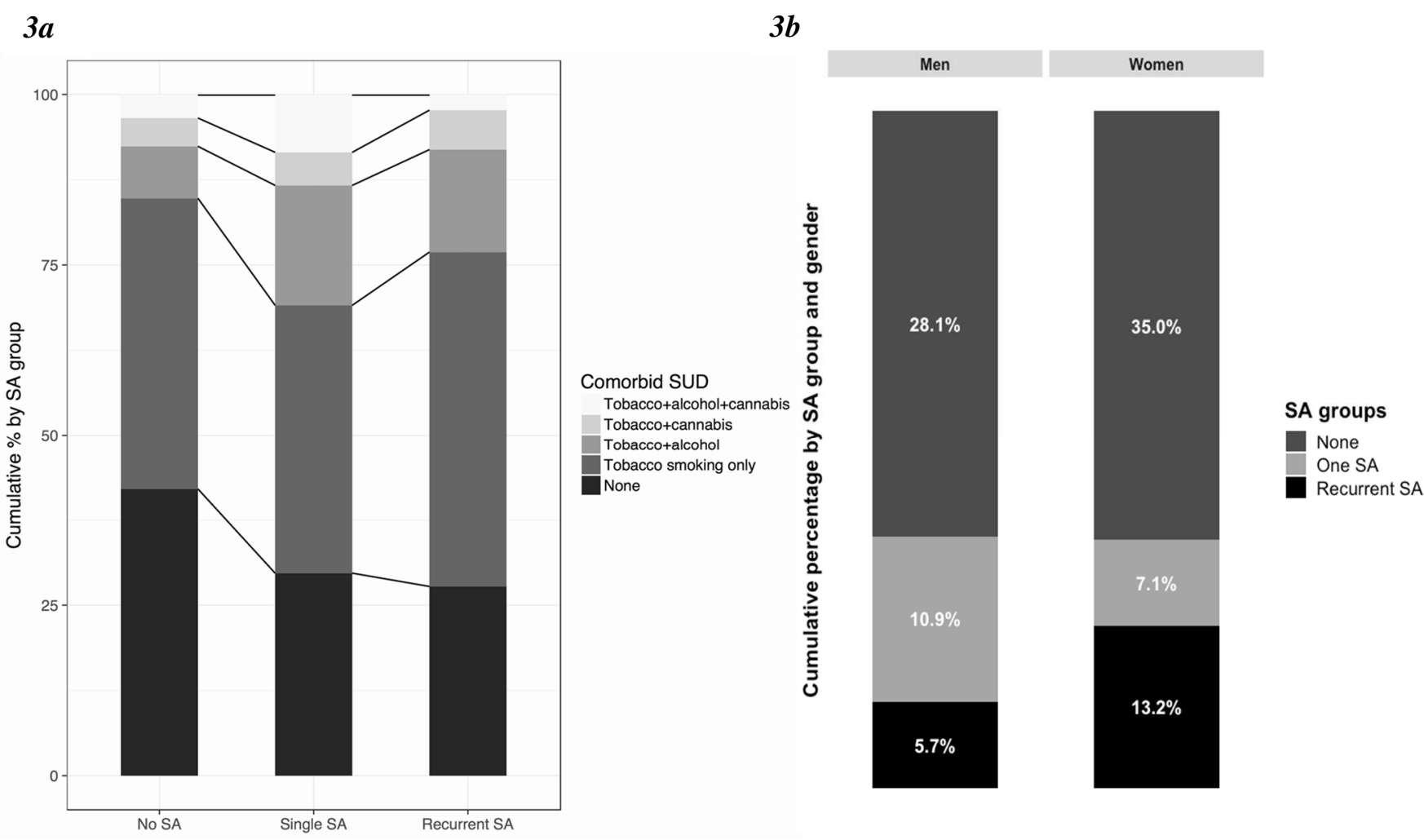

SUD, substance use disorder; SA, suicide attempt; AUD, alcohol use disorder; CUD, cannabis use disorder. Fig. 3a: Chi-squared $=37.949, p<0.001$; fig. 3b, Chi-squared $=11.609, p=0.003$.

Multinomial logistic regression (Table 3) showed that tobacco smoking was associated with recurrent SA independently from other SUDs. SUD profiles consisting of one SUD in addition to tobacco smoking showed the strongest associations with single (tobacco+AUD) and recurrent SA (tobacco+AUD, tobacco+CUD). Finally, tobacco+AUD+CUD was specifically associated with single SA, while female gender was linked to any SA. There was no evidence of multicollinearity (all VIF < 1.52) and Hosmer-Lemeshow test was not significant. 
Table 3: multinomial logistic regression with the presence or recurrence of SA as dependent variable and the absence of $\mathrm{SA}$ as reference variable.

Initial model (not shown): gender, country of inclusion, marital status, polarity at onset of $B D$, rate of mood episodes per year of illness, history of mixed episode, SUD groups, $1^{\text {st }}$ degree family history of mood disorder.

Final model (presented): variables that remained significant after backward, stepwise elimination based on largest to smallest $\mathrm{p}$-values.

Odds ratios (ORs) and 95\% confidence intervals (95\% CIs) are displayed.

\begin{tabular}{|c|c|c|c|c|}
\hline & & One lifetime $S A$ & $\begin{array}{c}\text { Recurrent lifetime } \\
\text { SA }\end{array}$ & $\begin{array}{l}\text { Recurrent vs. } \\
\text { single } S A\end{array}$ \\
\hline \multicolumn{2}{|c|}{ Gender (women vs. men) } & $1.48(1.01-2.18)^{*}$ & $2.23(1.51-3.29)^{* * *}$ & $1.5(0.93-2.41)$ \\
\hline \multicolumn{2}{|c|}{ Country (France $v s$. Norway) } & $1.38(0.92-2.08)$ & $1.98(1.3-3.03)^{* *}$ & $1.43(0.85-2.41)$ \\
\hline \multicolumn{2}{|c|}{$\begin{array}{l}\text { Polarity at onset of BD } \\
\text { (depressive } v s . \text { (hypo)manic) }\end{array}$} & $1.61(1.1-2.37)^{*}$ & $1.78(1.22-2.62)^{* *}$ & $1.11(0.68-1.79)$ \\
\hline \multirow{4}{*}{$\begin{array}{l}\text { Comorbid } \\
\text { SUD } \\
\text { (no SUD as } \\
\text { reference } \\
\text { group) }\end{array}$} & Tobacco smoking only & $1.36(0.89-2.08)$ & $1.75(1.16-2.63)^{* *}$ & $1.29(0.76-2.17)$ \\
\hline & Tobacco + AUD & $3.7(2.05-6.67) * * *$ & $3.58(1.94-6.59)^{* * *}$ & $0.97(0.49-1.92)$ \\
\hline & Tobacco + CUD & $1.71(0.68-4.26)$ & $2.65(1.15-6.1)^{* *}$ & $1.55(0.54-4.46)$ \\
\hline & Tobacco + AUD + CUD & $3.73(1.67-8.18)^{*}$ & $1.11(0.35-3.5)$ & $0.3(0.09-0.99)^{*}$ \\
\hline
\end{tabular}

SA, suicide attempt; SUD, substance use disorder; BD, bipolar disorder; AUD, alcohol use disorder; CUD, cannabis use disorder. ${ }^{*} \mathrm{p}<0.05 ; * * \mathrm{p}<0.01 ; * * \mathrm{p}<0.001$.

Finally, we conducted sensitivity analysis by performing multinomial regression with recurrent SA as a dependent variable in each country subsample separately, limited to current tobacco smokers in the French subsample so as to maintain comparability (Supplementary Table 2), and based on the independent factors listed in Table 3. This analysis confirmed the three main findings obtained in the whole sample: significant relationships between recurrent SA and tobacco smoking and depressive onset polarity, and between both single and recurrent SA and comorbid tobacco smoking + AUD. History of mixed episode shortly failed to reach 
significance of association in the French subsample $(p=0.056)$. In the Norwegian subsample, tobacco+CUD were further associated with both SA phenotypes, although with borderline statistical stablility given the very wide confidence intervals of both odds ratios. We took advantage from this country-specific analysis to test the differences in SA history between current vs. former tobacco smokers, thus in the French subsample only (supplementary Table 3). We found that current, but not former daily tobacco smokers, had an increased risk of reccurent $\mathrm{SA}(\mathrm{OR}=1.83,95 \% \mathrm{CI}=1.08-3.12, p=0.0025)$.

\section{Discussion}

In a large sample of patients with $\mathrm{BD}$, tobacco smoking was independently associated with recurrent SA, even in the absence of other SUDs. When tobacco smoking was comorbid with AUD or CUD, this association was stronger. Concurrently, the present study also evidenced associations between recurrent $\mathrm{SA}$ and depressive polarity at onset of $\mathrm{BD}$, history of mixed episodes and female gender, the latter encouraging further gender-stratified analyses. Associations between current tobacco smoking and recurrent SA, as well as those between AUD and both SA phenotypes and polarity at BD onset and recurrent SA, were replicated independently in both country subsamples. Moreover, in the French subsample where the group of former smokers was sub-categorized, we found that current smoking, but not former smoking, was independently associated with recurrent SA as compared to never smoking.

The association between tobacco smoking and recurrent SA may be dependent on the level of exposure to tobacco smoking (Lopez-Castroman et al., 2016a). Thus, current smokers had a significantly higher median of pack-years in the SA and recurrent SA groups than in the nonSA group (Table 2), but this relationship was lost after adjustment for confounders (regression analysis on current smokers, pack-years not shown in supplementary Table 2 due to lack of significance with both $p$-values $=1$ ). Current, but not former smokers in the French subsample 
had an increased risk for recurrent SA (supplementary Table 3), the results overall highlighting that the risk of recurrent SA was carried by the current smokers' group.

In preclinical models, the modulation of nicotinic receptors in the brain increased impulsivity and altered decision-making (Nees, 2015), both being involved in SA risk (Dalley and Robbins, 2017; Dombrovski and Hallquist, 2017). In patients assessed after an index SA from the emergency room, an interaction between heavy tobacco smoking and impulsivisty was found to increase the repetition of SA during prospective follow-up (Lopez-Castroman et al., 2016a). However, in BD patients, this link was first suggested in 2009 (Ostacher et al., 2009), but not confirmed in a more recent study that included BD patients thoroughly assessed for impulsiveness, clinical course and suicidal behavior (Etain et al., 2013). Although these data help prefiguring a neurobiological framework to the links between tobacco smoking and SAs, further studies in BD should use more experimental designs to assess the associations between tobacco smoking and impulsivity levels, together with clinical studies incorporating possible risk factors for recurrent SA.

AUD (combined with tobacco smoking) was strongly associated with both single and recurrent SA in the present sample and in both country subsamples (supplementary Table 2), which may reflect the strong relationship between AUD and SA in BD in general, regardless of recurrence (Schaffer et al., 2015).

Conversely, CUD (combined with tobacco smoking) was independently associated with recurrent SA in the present sample (but it was only replicated in the Norwegian subsample, supplementary Table 3). We previously reported the absence of association between lifetime CUD and lifetime SA (without further specification) (Lagerberg et al., 2016), but it seems that focusing on a more severe suicidal outcome uncovered a more specific link. Indirect evidence support this association, since CUD has been associated with (i) any SA in a national registry study (Østergaard et al., 2017), but only in people with BD; (ii) recurrent suicidal ideation, 
among other substances of abuse, in young adults without psychiatric disorders (Dugas et al., 2015); (iii) a lower age at first SA in psychiatric inpatients (Slama et al., 2009) and (iv) an early $\mathrm{AAO}$ of $\mathrm{BD}$ and a higher number of previous $\mathrm{SA}$ in a first-treatment $\mathrm{BD}$ sample (Kvitland et al., 2016). These data suggest, at least, that cannabis misuse is associated with a larger window of exposure to risk factors for recurrent SA. In the present sample, participants with CUD were signifanctly younger than those without, and both groups tended to exhibit higher rate of SA/year of BD than their counterparts (data not shown). Moreover, continued cannabis use has been associated with mixed episodes in BD (Bally et al., 2014), as was CUD in the present sample $\left(\mathrm{Chi}^{2}\right.$ test $\left.=16.965, \mathrm{p}=9.4 \times 10^{-3}\right)$. Further investigation regarding the pathway between tobacco and cannabis misuse and their links with mixed episodes, AAO of $\mathrm{BD}$ and age at first $\mathrm{SA}$ is warranted to better characterize their relationships with recurrent SA. The lack of association between the combination of tobacco smoking, CUD and AUD and recurrent SA was somewhat unexpected. This may be a false negative due to the low number of cases presenting with all three SUDs $(n=4)$ in the recurrent SA group, which was conserved in all analyses for the sake of clinical representativeness.

Recurrent SA have been associated with female gender in clinical samples (Icick et al., 2018; Monnin et al., 2012) but was not identified in a meta-analysis of unselected population studies (Cornaggia et al., 2013) nor, to the best of our knowledge, in BD (Arici et al., 2018; Michaelis et al., 2003). The discrepancy between the present study and these two previous BD studies may be explained by increased statistical power due to our larger sample size or to sampling issues. Likewise, the association between mixed episodes and recurrent SA had not been consistently evidenced, although there are reports linking mixed episodes with recurrent suicidal ideation (Goldberg et al., 1998) and repetition of SA (Persons et al., 2018). It is noticeable that mixed episodes have also been associated with rapid cycling and SUD (Carvalho et al., 2014), both being plausibly associated with recurrent SA. We also confirmed 
a previously-reported association between depressive polarity at onset of BD and recurrent SA (Neves et al., 2009), which was replicated in both country subsamples. Both results regarding mixed episodes and polarity at onset seemed specific in our sample, given that it was not confounded by the rate of mood episodes over the course of BD.

The present study has several strengths. It relies on the extensive assessement of a large sample of patients by structured interviews across a wide range of clinical variables, while using stringent phenotypes for $\mathrm{BD}$, suicidal outcomes and SUDs. The data on SA is expectedly reliable, because the risk of misclassification bias was reduced by using multipleitems assessment (Hom et al., 2016) (supplementary Methods) and by focusing on a stringent phenotype (Forman et al., 2004), which may have further limited the risk for inconsistent reporting of SA (Hart et al., 2013). Cases with BD 'not otherwise specified' were excluded to enchance the face validity of the sample. Not applying correction for multiple testing decreased type II error, since it allowed for identifying both female gender and mixed states as risk factors for recurrent SA, noticing that the selection of variables would have eventually been similar under Bonferroni correction. The regression model was performed with 752 cases and yielded high significance and good stability. Finally, in our sample, both the rates of SA and the proportion of recurrent vs. single SAs fell within the range of BD samples described elsewhere (Arici et al., 2018; Michaelis et al., 2003; Schaffer et al., 2015). The relatively low prevalence of comorbid SUD in our sample may reflect a common issue when studying addictive comorbidity among participants referred to specialized care for BD (Henry et al., 2015), as compared to those referred to acute inpatient wards or addiction clinics (Langås et al., 2012). It may also be related to issues in diagnostic accuracy (Hasin et al., 2006) and, possibly, to the underreporting of substance use and misuse by patients seen in psychiatric $v s$. addiction settings. 
The study also has limitations. The study was retrospective, which may have introduced recall bias that could be more important in participants with more severe/comorbid BD. The study was a secondary analysis of primary data collected from studies with somewhat different foci (genetics in France, early illness phases in Norway), which is likely to have introduced some selection biases. Thus, recurrent SA were significantly more frequent in the French vs. Norwegian sample (Table 1), even after controlling for confounding factors (Table 3). Table 1 and Figure 2 show further subsample differences. Compared to Norwegian participants, the French were also significantly older, which is likely explained by the focus of the Norwegian study toward first treatment patients. Besides, Norwegian participants lived more frequently alone than the French, probably due to their younger age. French participants also had a higher prevalence of lifetime SA and mixed episodes. It is noticeable that both suicidal behavior and tobacco smoking are highly prevalent in France (Giovino et al., 2012; Nock et al., 2009). As regards the inclusion of former tobacco smokers in the Norwegian non-smokers group, whilst they were regarded as lifetime tobacco smokers in France, we performed sensitivity analyses in current smokers only and to compare former vs. current smokers with regards to SA risk (supplementary Tables $1 \& 3$ ). Overall, there might have been some residual confounding effects of cross-national sampling and assessment procedures, although they were mostly similar (see supplementary Methods for SA history collection). Finally, it is noticeable that adjusting the duration of BD by the age at interview - both being lower in the Norwegian subsample - the resulting ratio did not differ between participants from Norway vs. France.

There were other limitations. The study was retrospective, which may have introduced recall bias that could be more important in participants with more severe/comorbid BD. We did not assess distal/lifetime risk factors such as childhood trauma, anxiety and personality disorders, which are possibly associated with with recurrent SA (Arici et al., 2018) in complex clinical 
patterns including increased risk for SUD comorbidity (Salloum and Brown, 2017) and shared psychological dimensions (e.g. affective lability, impulsiveness, hostility) (Aas et al., 2017; Etain et al., 2017, 2013). This is especially lacking regarding impulsivity and reward processing, which are major modulators of the link between trait and state vulnerability to suicidal behavior, in the framework of the stress-diathesis theory of suicidal outcomes (Malhi et al., 2018). Apart from tobacco smoking, we did not consider quantitative measures of exposure to addictive substances, although they may have been useful in terms of relative exposure to different risk factors and outcomes (Kennedy et al., 2015). Finally, due to crosssectional design, lifetime suicidal behavior was a right-censored variable in the study, so that new SAs may have occurred after participants' assessments (thus with potential misclassification in terms of SA group).

The associations evidenced in the present study are likely bi-directional and partly result from a shared liability of BD-SUD toward recurrent SA without any possible conclusion about causal inference. It is noticeable, however, that emerging data suggest such a causal relationship between smoking outcomes and both mood states (Taylor et al., 2014) and suicide risk (Evins et al., 2017; Grucza et al., 2014). With that regard, all their possible links (Hughes, 2008) will have to be investigated if one were to address the causality issue. Still, we have added important pieces of evidence regarding liability patterns of recurrent SA and SUDs in BD, especially by attempting to differentiate the factors associated with either single, recurrent SA, or both. Such vulnerability could further interact with specific stress comorbidity patterns to increase suicidal risk, especially toward the most burdensome suicidal outcomes. To our knowledge, no study to date has sought to determine whether treating SUD could decrease the incidence of SAs in $\mathrm{BD}$, although this benefit has been strongly established as regards e.g. the specialized treatment of heroin dependence (Darke and Ross, 2002). This would be particularly relevant as regards nicotine dependence, the treatment of which is well- 
defined and shows fair to good response rates, even in people with $\mathrm{BD}$, a majority of whom are willing to undergo such treatment (Evins et al., 2015; West et al., 2018).

\section{References}

Aas, M., Etain, B., Bellivier, F., Henry, C., Lagerberg, T., Ringen, A., Agartz, I., Gard, S., Kahn, J.-P., Leboyer, M., Andreassen, O.A., Melle, I., 2014. Additive effects of childhood abuse and cannabis abuse on clinical expressions of bipolar disorders. Psychol Med 44, 1653-1662. https://doi.org/10.1017/S0033291713002316

Aas, M., Henry, C., Bellivier, F., Lajnef, M., Gard, S., Kahn, J.-P., Lagerberg, T.V., Aminoff, S.R., Bjella, T., Leboyer, M., Andreassen, O.A., Melle, I., Etain, B., 2017. Affective lability mediates the association between childhood trauma and suicide attempts, mixed episodes and co-morbid anxiety disorders in bipolar disorders. Psychol Med 47, 902-912. https://doi.org/10.1017/S0033291716003081

American Association of Suicidology, 2013. Risk factors for suicide and suicidal behaviors I. American Association of Suicidology.

Arici, C., Cremaschi, L., Dobrea, C., Vismara, M., Grancini, B., Benatti, B., Buoli, M., Miller, S., Ketter, T.A., Altamura, A.C., Dell'Osso, B., 2018. Differentiating multiple vs single lifetime suicide attempters with bipolar disorders: A retrospective study. Comprehensive Psychiatry 80, 214222. https://doi.org/10.1016/j.comppsych.2017.10.006

Bally, N., Zullino, D., Aubry, J.-M., 2014. Cannabis use and first manic episode. J Affect Disord 165, 103-108. https://doi.org/10.1016/j.jad.2014.04.038

Carrà, G., Bartoli, F., Crocamo, C., Brady, K.T., Clerici, M., 2015. Cannabis use disorder as a correlate of suicide attempts among people with bipolar disorder. Bipolar Disord 17, 113-114. https://doi.org/10.1111/bdi.12282

Carrà, G., Bartoli, F., Crocamo, C., Brady, K.T., Clerici, M., 2014. Attempted suicide in people with cooccurring bipolar and substance use disorders: systematic review and meta-analysis. J Affect Disord 167, 125-135. https://doi.org/10.1016/j.jad.2014.05.066

Carvalho, A.F., Dimellis, D., Gonda, X., Vieta, E., McIntyre, R.S., Fountoulakis, K.N., 2014. Rapid cycling in bipolar disorder: a systematic review. J Clin Psychiatry 75, e578-586. https://doi.org/10.4088/JCP.13r08905

Colborn, V.A., LaCroix, J.M., Neely, L.L., Tucker, J., Perera, K., Daruwala, S.E., Grammer, G., Weaver, J., Ghahramanlou-Holloway, M., 2017. Motor impulsivity differentiates between psychiatric inpatients with multiple versus single lifetime suicide attempts. Psychiatry Research 253, 18 21. https://doi.org/10.1016/j.psychres.2017.03.026

Cornaggia, C., Beghi, Rosenbaum, Cerri, 2013. Risk factors for fatal and nonfatal repetition of suicide attempts: a literature review. Neuropsychiatric Disease and Treatment 1725. https://doi.org/10.2147/NDT.S40213

Costa, L. da S., Alencar, Á.P., Nascimento Neto, P.J., dos Santos, M. do S.V., da Silva, C.G.L., Pinheiro, S. de F.L., Silveira, R.T., Bianco, B.A.V., Pinheiro, R.F.F., de Lima, M.A.P., Reis, A.O.A., Rolim Neto, M.L., 2015. Risk factors for suicide in bipolar disorder: a systematic review. J Affect Disord 170, 237-254. https://doi.org/10.1016/j.jad.2014.09.003

Dalley, J.W., Robbins, T.W., 2017. Fractionating impulsivity: neuropsychiatric implications. Nature Reviews Neuroscience 18, 158. https://doi.org/10.1038/nrn.2017.8

Darke, S., Ross, J., 2002. Suicide among heroin users: rates, risk factors and methods. Addiction 97, 1383-1394. 
Dombrovski, A.Y., Hallquist, M.N., 2017. The decision neuroscience perspective on suicidal behavior: evidence and hypotheses. Curr Opin Psychiatry 30, 7-14.

https://doi.org/10.1097/YCO.0000000000000297

Ducasse, D., Jaussent, I., Guillaume, S., Azorin, J.M., Bellivier, F., Belzeaux, R., Bougerol, T., Etain, B., Gard, S., Henry, C., Kahn, J.P., Leboyer, M., Loftus, J., Passerieux, C., Courtet, P.H., Olié, E., FondaMental Advanced Centers of Expertise in Bipolar Disorders (FACE-BD) Collaborators, 2015. Increased risk of suicide attempt in bipolar patients with severe tobacco dependence. J Affect Disord 183, 113-118. https://doi.org/10.1016/j.jad.2015.04.038

Dugas, E.N., Low, N.C., O'Loughlin, E.K., O'Loughlin, J.L., 2015. Recurrent suicidal ideation in young adults. Can J Public Health 106, e303-307.

Etain, B., Lajnef, M., Henry, C., Aubin, V., Azorin, J.M., Bellivier, F., Bougerol, T., Courtet, P., Gard, S., Kahn, J.P., Passerieux, C., Leboyer, M., FACE-BD Clinical Coordinating Center (FondaMental Foundation), FACE-BD Data Coordinating Center (FondaMental Foundation), FACE-BD Clinical Sites and Principal Collaborators in France, 2017. Childhood trauma, dimensions of psychopathology and the clinical expression of bipolar disorders: A pathway analysis. J Psychiatr Res 95, 37-45. https://doi.org/10.1016/j.jpsychires.2017.07.013

Etain, B., Mathieu, F., Liquet, S., Raust, A., Cochet, B., Richard, J.R., Gard, S., Zanouy, L., Kahn, J.P., Cohen, R.F., Bougerol, T., Henry, C., Leboyer, M., Bellivier, F., 2013. Clinical features associated with trait-impulsiveness in euthymic bipolar disorder patients. J Affect Disord 144, 240-247. https://doi.org/10.1016/j.jad.2012.07.005

Evins, A.E., Cather, C., Laffer, A., 2015. Treatment of Tobacco Use Disorders in Smokers with Serious Mental Illness: Toward Clinical Best Practices. Harv Rev Psychiatry 23, 90-98. https://doi.org/10.1097/HRP.0000000000000063

Evins, A.E., Korhonen, T., Kinnunen, T.H., Kaprio, J., 2017. Prospective association between tobacco smoking and death by suicide: a competing risks hazard analysis in a large twin cohort with 35-year follow-up. Psychol Med 47, 2143-2154. https://doi.org/10.1017/S0033291717000587

Forman, E.M., Berk, M.S., Henriques, G.R., Brown, G.K., Beck, A.T., 2004. History of multiple suicide attempts as a behavioral marker of severe psychopathology. Am J Psychiatry 161, 437-443. https://doi.org/10.1176/appi.ajp.161.3.437

Giovino, G.A., Mirza, S.A., Samet, J.M., Gupta, P.C., Jarvis, M.J., Bhala, N., Peto, R., Zatonski, W., Hsia, J., Morton, J., Palipudi, K.M., Asma, S., GATS Collaborative Group, 2012. Tobacco use in 3 billion individuals from 16 countries: an analysis of nationally representative cross-sectional household surveys. Lancet 380, 668-679. https://doi.org/10.1016/S0140-6736(12)61085-X

Goldberg, J.F., Garno, J.L., Leon, A.C., Kocsis, J.H., Portera, L., 1998. Association of recurrent suicidal ideation with nonremission from acute mixed mania. Am J Psychiatry 155, 1753-1755. https://doi.org/10.1176/ajp.155.12.1753

Goodfellow, B., Kõlves, K., de Leo, D., 2017. Contemporary Nomenclatures of Suicidal Behaviors: A Systematic Literature Review. Suicide Life Threat Behav. https://doi.org/10.1111/sltb.12354

Grucza, R.A., Plunk, A.D., Krauss, M.J., Cavazos-Rehg, P.A., Deak, J., Gebhardt, K., Chaloupka, F.J., Bierut, L.J., 2014. Probing the Smoking-Suicide Association: Do Smoking Policy Interventions Affect Suicide Risk? Nicotine Tob Res 16, 1487-1494. https://doi.org/10.1093/ntr/ntu106

Hart, S.R., Musci, R.J., lalongo, N., Ballard, E.D., Wilcox, H.C., 2013. Demographic and clinical characteristics of consistent and inconsistent longitudinal reporters of lifetime suicide attempts in adolescence through young adulthood. Depress Anxiety 30, 997-1004. https://doi.org/10.1002/da.22135

Hasin, D., Samet, S., Nunes, E., Meydan, J., Matseoane, K., Waxman, R., 2006. Diagnosis of comorbid psychiatric disorders in substance users assessed with the Psychiatric Research Interview for Substance and Mental Disorders for DSM-IV. Am J Psychiatry 163, 689-696. https://doi.org/10.1176/ajp.2006.163.4.689 
Hayes, J.F., Miles, J., Walters, K., King, M., Osborn, D.P.J., 2015. A systematic review and metaanalysis of premature mortality in bipolar affective disorder. Acta Psychiatr Scand 131, 417425. https://doi.org/10.1111/acps.12408

Henry, C., Etain, B., Godin, O., Dargel, A.A., Azorin, J.-M., Gard, S., Bellivier, F., Bougerol, T., Kahn, J.P., Passerieux, C., Aubin, V., Courtet, P., Leboyer, M., FACE-BD group, 2015. Bipolar patients referred to specialized services of care: Not resistant but impaired by sub-syndromal symptoms. Results from the FACE-BD cohort. Aust N Z J Psychiatry 49, 898-905. https://doi.org/10.1177/0004867415585582

Hom, M.A., Joiner, T.E., Bernert, R.A., 2016. Limitations of a single-item assessment of suicide attempt history: Implications for standardized suicide risk assessment. Psychol Assess 28, 1026-1030. https://doi.org/10.1037/pas0000241

Hughes, J.R., 2008. Smoking and suicide: A brief overview. Drug and Alcohol Dependence 98, 169178. https://doi.org/10.1016/j.drugalcdep.2008.06.003

Hughes, J.R., Shiffman, S., Naud, S., Peters, E.N., 2017. Day to day Variability in Self-Reported Cigarettes Per Day. Nicotine Tob. Res. https://doi.org/10.1093/ntr/ntx057

Hunt, G.E., Malhi, G.S., Cleary, M., Lai, H.M.X., Sitharthan, T., 2016a. Prevalence of comorbid bipolar and substance use disorders in clinical settings, 1990-2015: Systematic review and metaanalysis. J Affect Disord 206, 331-349. https://doi.org/10.1016/j.jad.2016.07.011

Hunt, G.E., Malhi, G.S., Cleary, M., Lai, H.M.X., Sitharthan, T., 2016b. Comorbidity of bipolar and substance use disorders in national surveys of general populations, 1990-2015: Systematic review and meta-analysis. J Affect Disord 206, 321-330. https://doi.org/10.1016/j.jad.2016.06.051

Icick, R., Vorspan, F., Karsinti, E., Ksouda, K., Lépine, J.-P., Brousse, G., Mouly, S., Bellivier, F., Bloch, V., 2018. Gender-specific study of recurrent suicide attempts in outpatients with multiple substance use disorders. Journal of Affective Disorders 241, 546-553. https://doi.org/10.1016/j.jad.2018.08.076

Janiri, D., Di Nicola, M., Martinotti, G., Janiri, L., 2017. Who's the Leader, Mania or Depression? Predominant Polarity and Alcohol/Polysubstance Use in Bipolar Disorders. Curr Neuropharmacol 15, 409-416. https://doi.org/10.2174/1570159X14666160607101400

Jylhä, P.J., Rosenström, T., Mantere, O., Suominen, K., Melartin, T.K., Vuorilehto, M.S., Holma, M.K., Riihimäki, K.A., Oquendo, M.A., Keltikangas-Järvinen, L., Isometsä, E.T., 2016. Temperament, character, and suicide attempts in unipolar and bipolar mood disorders. J Clin Psychiatry 77, 252-260. https://doi.org/10.4088/JCP.14m09472

Kennedy, M.C., Marshall, B.D.L., Hayashi, K., Nguyen, P., Wood, E., Kerr, T., 2015. Heavy alcohol use and suicidal behavior among people who use illicit drugs: A cohort study. Drug Alcohol Depend 151, 272-277. https://doi.org/10.1016/j.drugalcdep.2015.03.006

Kvitland, L.R., Melle, I., Aminoff, S.R., Lagerberg, T.V., Andreassen, O.A., Ringen, P.A., 2016. Cannabis use in first-treatment bipolar I disorder: relations to clinical characteristics. Early Intervention in Psychiatry 10, 36-44. https://doi.org/10.1111/eip.12138

Lagerberg, T.V., Icick, R., Andreassen, O.A., Ringen, P.A., Etain, B., Aas, M., Henry, C., Bjella, T.D., Melle, I., Bellivier, F., 2016. Cannabis use disorder is associated with greater illness severity in tobacco smoking patients with bipolar disorder. J Affect Disord 190, 286-293. https://doi.org/10.1016/j.jad.2015.10.023

Langås, A.-M., Malt, U.F., Opjordsmoen, S., 2012. Substance use disorders and comorbid mental disorders in first-time admitted patients from a catchment area. Eur Addict Res 18, 16-25. https://doi.org/10.1159/000332234

Large, M., Kaneson, M., Myles, N., Myles, H., Gunaratne, P., Ryan, C., 2016. Meta-Analysis of Longitudinal Cohort Studies of Suicide Risk Assessment among Psychiatric Patients: Heterogeneity in Results and Lack of Improvement over Time. PLOS ONE 11, e0156322. https://doi.org/10.1371/journal.pone.0156322 
Liu, Y., Zhang, J., Sun, L., 2017. Who are likely to attempt suicide again? A comparative study between the first and multiple timers. Comprehensive Psychiatry 78, 54-60.

https://doi.org/10.1016/j.comppsych.2017.07.007

Lopez-Castroman, J., Cerrato, L., Beziat, S., Jaussent, I., Guillaume, S., Courtet, P., 2016a. Heavy tobacco dependence in suicide attempters making recurrent and medically serious attempts. Drug Alcohol Depend 160, 177-182. https://doi.org/10.1016/j.drugalcdep.2016.01.004

Lopez-Castroman, J., Nogue, E., Guillaume, S., Picot, M.C., Courtet, P., 2016b. Clustering Suicide Attempters: Impulsive-Ambivalent, Well-Planned, or Frequent. J Clin Psychiatry 77, e711-718. https://doi.org/10.4088/JCP.15m09882

Lopez-Castroman, J., Perez-Rodriguez, M. de las M., Jaussent, I., Alegria, A.A., Artes-Rodriguez, A., Freed, P., Guillaume, S., Jollant, F., Leiva-Murillo, J.M., Malafosse, A., Oquendo, M.A., de Prado-Cumplido, M., Saiz-Ruiz, J., Baca-Garcia, E., Courtet, P., European Research Consortium for Suicide (EURECA), 2011. Distinguishing the relevant features of frequent suicide attempters. J Psychiatr Res 45, 619-625. https://doi.org/10.1016/j.jpsychires.2010.09.017

Malhi, G.S., Outhred, T., Das, P., Morris, G., Hamilton, A., Mannie, Z., 2018. Modeling suicide in bipolar disorders. Bipolar Disorders 20, 334-348. https://doi.org/10.1111/bdi.12622

Michaelis, B.H., Goldberg, J.F., Singer, T.M., Garno, J.L., Ernst, C.L., Davis, G.P., 2003. Characteristics of first suicide attempts in single versus multiple suicide attempters with bipolar disorder. Comprehensive Psychiatry 44, 15-20. https://doi.org/10.1053/comp.2003.50004

Mitchell, M.R., Potenza, M.N., 2014. Addictions and Personality Traits: Impulsivity and Related Constructs. Curr Behav Neurosci Rep 1, 1-12. https://doi.org/10.1007/s40473-013-0001-y

Monnin, J., Thiemard, E., Vandel, P., Nicolier, M., Tio, G., Courtet, P., Bellivier, F., Sechter, D., Haffen, E., 2012. Sociodemographic and psychopathological risk factors in repeated suicide attempts: gender differences in a prospective study. J Affect Disord 136, 35-43. https://doi.org/10.1016/j.jad.2011.09.001

Montgomery, S.A., Asberg, M., 1979. A new depression scale designed to be sensitive to change. $\mathrm{Br}$ J Psychiatry 134, 382-389.

Mork, E., Walby, F.A., Harkavy-Friedman, J.M., Barrett, E.A., Steen, N.E., Lorentzen, S., Andreassen, O.A., Melle, I., Mehlum, L., 2013. Clinical characteristics in schizophrenia patients with or without suicide attempts and non-suicidal self-harm - a cross-sectional study. BMC Psychiatry 13, 255. https://doi.org/10.1186/1471-244X-13-255

National Collaborating Centre for Mental Health (UK), 2004. Self-Harm: The Short-Term Physical and Psychological Management and Secondary Prevention of Self-Harm in Primary and Secondary Care, National Institute for Health and Clinical Excellence: Guidance. British Psychological Society, Leicester (UK).

Nees, F., 2015. The nicotinic cholinergic system function in the human brain. Neuropharmacology 96 , 289-301. https://doi.org/10.1016/j.neuropharm.2014.10.021

Neves, F.S., Malloy-Diniz, L.F., Barbosa, I.G., Brasil, P.M., Corrêa, H., 2009. Bipolar disorder first episode and suicidal behavior: are there differences according to type of suicide attempt? Rev Bras Psiquiatr 31, 114-118.

Nock, M.K., Hwang, I., Sampson, N., Kessler, R.C., Angermeyer, M., Beautrais, A., Borges, G., Bromet, E., Bruffaerts, R., Girolamo, G. de, Graaf, R. de, Florescu, S., Gureje, O., Haro, J.M., Hu, C., Huang, Y., Karam, E.G., Kawakami, N., Kovess, V., Levinson, D., Posada-Villa, J., Sagar, R., Tomov, T., Viana, M.C., Williams, D.R., 2009. Cross-National Analysis of the Associations among Mental Disorders and Suicidal Behavior: Findings from the WHO World Mental Health Surveys. PLOS Medicine 6, e1000123. https://doi.org/10.1371/journal.pmed.1000123

Olié, E., Seyller, M., Beziat, S., Loftus, J., Bellivier, F., Bougerol, T., Belzeaux, R., Azorin, J.M., Gard, S., Kahn, J.P., Passerieux, C., Leboyer, M., Etain, B., Henry, C., Courtet, P., 2015. Clinical and neuropsychological characteristics of euthymic bipolar patients having a history of severe suicide attempt. Acta Psychiatr Scand 131, 129-138. https://doi.org/10.1111/acps.12326

Oquendo, M.A., Kamali, M., Ellis, S.P., Grunebaum, M.F., Malone, K.M., Brodsky, B.S., Sackeim, H.A., Mann, J.J., 2002. Adequacy of antidepressant treatment after discharge and the occurrence 
of suicidal acts in major depression: a prospective study. Am J Psychiatry 159, 1746-1751. https://doi.org/10.1176/appi.ajp.159.10.1746

Ostacher, M.J., Lebeau, R.T., Perlis, R.H., Nierenberg, A.A., Lund, H.G., Moshier, S.J., Sachs, G.S., Simon, N.M., 2009. Cigarette smoking is associated with suicidality in bipolar disorder. Bipolar Disord 11, 766-771. https://doi.org/10.1111/j.1399-5618.2009.00744.x

$\emptyset$ stergaard, M.L.D., Nordentoft, M., Hjorth $\varnothing$ j, C., 2017. Associations between substance use disorders and suicide or suicide attempts in people with mental illness: a Danish nation-wide, prospective, register-based study of patients diagnosed with schizophrenia, bipolar disorder, unipolar depression or personality disorder. Addiction. https://doi.org/10.1111/add.13788

Perquier, F., Duroy, D., Oudinet, C., Maamar, A., Choquet, C., Casalino, E., Lejoyeux, M., 2017. Suicide attempters examined in a Parisian Emergency Department: Contrasting characteristics associated with multiple suicide attempts or with the motive to die. Psychiatry Research 253, 142-149. https://doi.org/10.1016/j.psychres.2017.03.035

Perroud, N., Baud, P., Mouthon, D., Courtet, P., Malafosse, A., 2011. Impulsivity, aggression and suicidal behavior in unipolar and bipolar disorders. Journal of Affective Disorders 134, 112118. https://doi.org/10.1016/j.jad.2011.05.048

Persons, J.E., Coryell, W.H., Solomon, D.A., Keller, M.B., Endicott, J., Fiedorowicz, J.G., 2018. Mixed State and Suicide: Is the effect of mixed state on suicidal behavior more than the sum of its parts? Bipolar Disord 20, 35-41. https://doi.org/10.1111/bdi.12538

Peters, E.N., Budney, A.J., Carroll, K.M., 2012. Clinical correlates of co-occurring cannabis and tobacco use: a systematic review. Addiction 107, 1404-1417. https://doi.org/10.1111/j.13600443.2012.03843.x

Pompili, M., Gonda, X., Serafini, G., Innamorati, M., Sher, L., Amore, M., Rihmer, Z., Girardi, P., 2013. Epidemiology of suicide in bipolar disorders: a systematic review of the literature. Bipolar Disord 15, 457-490. https://doi.org/10.1111/bdi.12087

Popovic, D., Torrent, C., Goikolea, J.M., Cruz, N., Sánchez-Moreno, J., González-Pinto, A., Vieta, E., 2014. Clinical implications of predominant polarity and the polarity index in bipolar disorder: a naturalistic study. Acta Psychiatr Scand 129, 366-374. https://doi.org/10.1111/acps.12179

Preisig, M., Fenton, B.T., Matthey, M.L., Berney, A., Ferrero, F., 1999. Diagnostic interview for genetic studies (DIGS): inter-rater and test-retest reliability of the French version. Eur Arch Psychiatry Clin Neurosci 249, 174-179.

R Core Team, 2019. R: A language and environment for statistical computing. R Foundation for Statistical Computing, Vienna, Austria.

R Studio Team, 2019. R Studio.

Ringen, P.A., Lagerberg, T.V., Birkenaes, A.B., Engn, J., Faerden, A., Jónsdottir, H., Nesvåg, R., Friis, S., Opjordsmoen, S., Larsen, F., Melle, I., Andreassen, O.A., 2008. Differences in prevalence and patterns of substance use in schizophrenia and bipolar disorder. Psychol Med 38, 1241-1249. https://doi.org/10.1017/\$003329170700236X

Salloum, I.M., Brown, E.S., 2017. Management of comorbid bipolar disorder and substance use disorders. Am J Drug Alcohol Abuse 43, 366-376. https://doi.org/10.1080/00952990.2017.1292279

Schaffer, A., Isometsä, E.T., Tondo, L., H Moreno, D., Turecki, G., Reis, C., Cassidy, F., Sinyor, M., Azorin, J.-M., Kessing, L.V., Ha, K., Goldstein, T., Weizman, A., Beautrais, A., Chou, Y.-H., Diazgranados, N., Levitt, A.J., Zarate, C.A., Rihmer, Z., Yatham, L.N., 2015. International Society for Bipolar Disorders Task Force on Suicide: meta-analyses and meta-regression of correlates of suicide attempts and suicide deaths in bipolar disorder. Bipolar Disord 17, 1-16. https://doi.org/10.1111/bdi.12271

Sher, L., Grunebaum, M.F., Burke, A.K., Chaudhury, S., Mann, J.J., Oquendo, M.A., 2017. Depressed Multiple-Suicide-Attempters - A High-Risk Phenotype. Crisis 1-9. https://doi.org/10.1027/0227-5910/a000475

Singhal, A., Ross, J., Seminog, O., Hawton, K., Goldacre, M.J., 2014. Risk of self-harm and suicide in people with specific psychiatric and physical disorders: comparisons between disorders using 
English national record linkage. J R Soc Med 107, 194-204.

https://doi.org/10.1177/0141076814522033

Slama, F., Courtet, P., Golmard, J.L., Mathieu, F., Guillaume, S., Yon, L., Jollant, F., Misson, H., Jaussent, I., Leboyer, M., Bellivier, F., 2009. Admixture analysis of age at first suicide attempt. J Psychiatr Res 43, 895-900. https://doi.org/10.1016/j.jpsychires.2009.01.007

Taylor, G., McNeill, A., Girling, A., Farley, A., Lindson-Hawley, N., Aveyard, P., 2014. Change in mental health after smoking cessation: systematic review and meta-analysis. BMJ 348, g1151.

Thomson, D., Berk, M., Dodd, S., Rapado-Castro, M., Quirk, S.E., Ellegaard, P.K., Berk, L., Dean, O.M., 2015. Tobacco Use in Bipolar Disorder. Clin Psychopharmacol Neurosci 13, 1-11. https://doi.org/10.9758/cpn.2015.13.1.1

Vajda, J., Steinbeck, K., 2000. Factors associated with repeat suicide attempts among adolescents. Aust N Z J Psychiatry 34, 437-445. https://doi.org/10.1080/j.1440-1614.2000.00712.x

West, R., Evins, A.E., Benowitz, N.L., Russ, C., McRae, T., Lawrence, D., St Aubin, L., Krishen, A., Maravic, M.C., Anthenelli, R.M., 2018. Factors associated with the efficacy of smoking cessation treatments and predictors of smoking abstinence in EAGLES. Addiction 113, 15071516. https://doi.org/10.1111/add.14208

Young, R.C., Biggs, J.T., Ziegler, V.E., Meyer, D.A., 1978. A rating scale for mania: reliability, validity and sensitivity. Br J Psychiatry 133, 429-435.

Zahl, D.L., Hawton, K., 2004. Repetition of deliberate self-harm and subsequent suicide risk: Longterm follow-up study of 11583 patients. The British Journal of Psychiatry 185, 70-75. https://doi.org/10.1192/bjp.185.1.70

Zatzick, D., Rowhani-Rahbar, A., Wan, J., Russo, J., Darnell, D., Ingraham, L., Whiteside, L.K., Guiney, R., Hedrick, M.K., Rivara, F.P., 2017. The Cumulative Burden of Psychiatric, Substance Use and Medical Disorders, and Re-hospitalization and Mortality after Injury. Psychiatr Serv 68, 596-602. https://doi.org/10.1176/appi.ps.201600311 